\title{
3D-Dynamic Modelling and Performance Analysis of Service Behavior for Beam Pumping Unit
}

\author{
Feng Zi-Ming $\mathbb{D}^{1},{ }^{1}$ Tan Jing-Jing, ${ }^{1}$ Sun Yanan, ${ }^{2}$ Zhang De-Shi, ${ }^{2}$ and Duan Wei-Bo ${ }^{1}$ \\ ${ }^{1}$ Machine Science and Engineering, Northeast Petroleum University, Daqing, China \\ ${ }^{2}$ Research Institute of Oil Production Engineering of Daqing Oilfield Company Limited, China \\ Correspondence should be addressed to Feng Zi-Ming; xueyuanfzm@163.com
}

Received 6 October 2017; Revised 10 April 2018; Accepted 16 May 2018; Published 12 July 2018

Academic Editor: Jian G. Zhou

Copyright (c) 2018 Feng Zi-Ming et al. This is an open access article distributed under the Creative Commons Attribution License, which permits unrestricted use, distribution, and reproduction in any medium, provided the original work is properly cited.

\begin{abstract}
In consideration of the rod, the tube, and the liquid column, a 3D dynamic model was established, which could be expressed as a set of partial differential equations. A measured torque curve and a calculated torque curve of Nanl-2-22 oil-well in Daqing oilfield were contrasted with each other which improved the rationality of this model. At last, we researched the influence of the stroke and the frequency of stroke on the displacement of rod, suspension velocity, suspension acceleration, polish rod load, and net torque of gearbox. This 3D dynamic model has a higher calculated accuracy and veracity and could be used to design and optimize the structure of rod pumping and the working process of pumping wells.
\end{abstract}

\section{Introduction}

A fast and accurate calculation of polished rod load was the prerequisite for optimization design of type selection, the reasonable matching design, fault diagnosis, and intelligent control of the beam pumping well system.

The earliest rod pumping system design was semiempirical design methods, such as "API Specification for Pumping Units". This method relied on the plunger diameter, the static fluid load, the rod size(s), the dynamic force, and the friction loads, which were all calculated by the semiempirical formulation. The semiempirical formulation had a lot of limitation for refined calculation. The first semiempirical modelling of rod pumping system was done by Kemelor [1]. Their efforts were then concentrated on the construction of an electrical analogue. Halderson [2] also established an analogue model. Many analogue models were built, but none of them completely and accurately solved the sucker-rod pump problem.

Norton [3] developed an analytical solution by an approximation method. This method was partially successful but was never widely applied. The next major development was by Snyder [4], who used a numerical technique to calculate the down hole force and displacement. This method was primarily for diagnosis of operating problem in existing wells. In 1963, Gibbs [5] presented a method that suitably generalized for a wider range of application. Many companies, such as Lufkin Foundry and Machine Company, made this method to be available as a commercial serviced by Sucker Rod Pump Analysis. It is a numerical technique programmed for solution on a digital computer.

Chacin and Purcupile [6] dispersed the rod string to be the spring mass system with damping, and they established the ordinary differential equations to describe the lumped mass element vibration law, and they established the system simulation model by use of the numerical integral method. In 1983, Doty and Schmidt [7] established a two-dimensional model of the coupled vibration of rod string and liquid column.

Lelia and Evans [8] had conducted further research about dynamic forecasting model of rod string and liquid column with coupling motion. They had carried on two hypotheses to the liquid column: one is that the liquid column was a single phase incompressible liquid, two is that the liquid column was a single-phase microcompressible, and it could be used difference method to calculate the numerical solution. In 1988, Yu [9] considered the fact of general unanchor of oil tubing in China; he comprehensively considered the sucker 
rod, liquid column, and the tubing string and established a $3 \mathrm{D}$ vibration model for prediction of polished rod load, but its limit condition for calculation was limiting its scope of application.

In 2010, Shardakov et al. [10] developed a new mathematical model of longitudinal vibrations of the sucker rod string and its numerical implementation. Its model can take into account strongly nonlinear forces resulting from pump valves and Coulomb's friction. The numerical results indicated that it shows rather good agreement between the numerical and experimental results. In 2013, Jiang et al. [11] developed a coupling mathematical optimized model of the prime motor and the walking beam pumping units to analyze the dynamics performance. In 2015, Ferrigno et al. [12] proposed a calculation algorithm using a combination of the motor performance analysis and the calculations based on API 11E, allowing us to determine the real torque of units in real time from telemetry, eliminating the need to make on-site surveys of the counterweighting of the unit.

In 2016, Lao and Zhou [13] developed a new direct calculation method that directly calculates the fluid force acting on the curved cylindrical surface of the rod element. They used the pump dynamometer cards as boundary conditions and solved the wave equations for sucker-rod pumping with more accuracy than before. In 2016, considering the limitation of simulation model of the deep well and ultradeep well, Xing [14] developed an improved simulation model of sucker rod pumping system. Xing concluded that, comparing with the steel rod, carbon fiber, and fiberglass rod, the resonant phenomenon of single rod is more likely to happen for the wire rope sucker rod. However, when sucker rod is double stage rod, the resonant phenomenon of fiberglass rod is more likely to happen than other rods.

In this paper, considering the static and dynamic and friction forces of the rod, the tube, and the liquid column, we established a mathematical calculation model named 3D dynamic wave model which was made up of a set of partial differential equations. By programming this dynamic model, we researched the impact of stroke and frequency of stroke on suspension velocity, suspension acceleration, polished rod load, and net torque of gearbox of CYJY10-3$37 \mathrm{HB}$ rod pumping. At the same time, the calculated data by this dynamic model had good meeting with the measured data. It provided an optional theoretical support for the typeselection and optimization design, the reasonable matching design, the fault diagnosis, and the intelligent control of the oil pumping well system.

\section{Dynamics Model of Pumping Unit System}

The polished rod load of pumping unit was the main basis factor for the optimum design and the swabbing technology design. The polished rod load was made up of the weight of the sucker rod and the liquid column, the inertia load, the load of vibration load, and the friction load. In order to calculate these loads accurately, the mechanical model of rod string was established, and it analyzed the influence factors, respectively. The suspended displacement, the suspended velocity, and the suspended acceleration were depicted in the literatures [15].

2.1. Rod-Tube-Fluid 3D Coupling Vibration Model. In order to simplify the dynamic model of rod pump system, the following were assumed:

(i) The beam pumping units are our research object, where rotate speed of gearbox crank is a constant variable.

(ii) There are no gassy bubbles in the liquid column and the liquid density $\rho_{f}$ is a constant.

(iii) The resistance of valve is ignored.

(iv) The dynamic viscosity of liquid column $\eta$, the back pressure of wellhead $P_{0}$, and the intake pressure of pump $P_{1}$ are all constants.

2.1.1. Dynamic Model of the Oil Rod. The rod element force diagram was as shown in Figure 1(a); we can see from the dynamic force equilibrium:

$$
\rho_{r} A_{r} \frac{\partial v_{r}}{\partial t}=\frac{\partial Q_{r}}{\partial x}+\rho_{r} A_{r} g\left(1-\frac{\rho_{f}}{\rho_{r}}\right)-F_{r}
$$

By the Hooke's law, the inner force relation of oil rod can be achieved:

$$
Q_{r}=E_{r} A_{r} \frac{\partial u}{\partial x}
$$

The following equation can be achieved by a partial derivative with time to the above equation:

$$
E_{r} A_{r} \frac{\partial v_{r}}{\partial x}=\frac{\partial Q_{r}}{\partial t}
$$

where

$$
\begin{aligned}
& v_{r}(x, t) \text { is rod velocity, } \mathrm{m} / \mathrm{s} ; \\
& Q_{r}(x, t) \text { is inner force of rod, } \mathrm{N} ; \\
& E_{r} \text { is rigidity of rod, } \mathrm{N} / \mathrm{m}^{2} ; \\
& A_{r} \text { is sectional area of } \mathrm{rod}, \mathrm{m}^{2} ; \\
& \rho_{r} \text { is density of rod, } \mathrm{kg} / \mathrm{m}^{3} ; \\
& \rho_{f} \text { is liquid density, } \mathrm{kg} / \mathrm{m}^{3} ; \\
& F_{r} \text { is resistance met with rod, N/m; } \\
& F_{f} \text { is resistance acted on the liquid, N/m. }
\end{aligned}
$$

2.1.2. Dynamic Model of the Oil Tube. A dynamic analysis of tube element was similar to rod model; two partial differential equations depicted rod movement was achieved as follows:

$$
\begin{aligned}
& \rho_{r}\left(A_{h}-A_{t}\right) \frac{\partial v_{t}}{\partial t}=\frac{\partial Q_{t}}{\partial x} \rho_{t} g\left(A_{h}-A_{t}\right)-F_{t} \\
& E_{t}\left(A_{h}-A_{t}\right) \frac{\partial v_{t}}{\partial x}=\frac{\partial Q_{t}}{\partial t}
\end{aligned}
$$




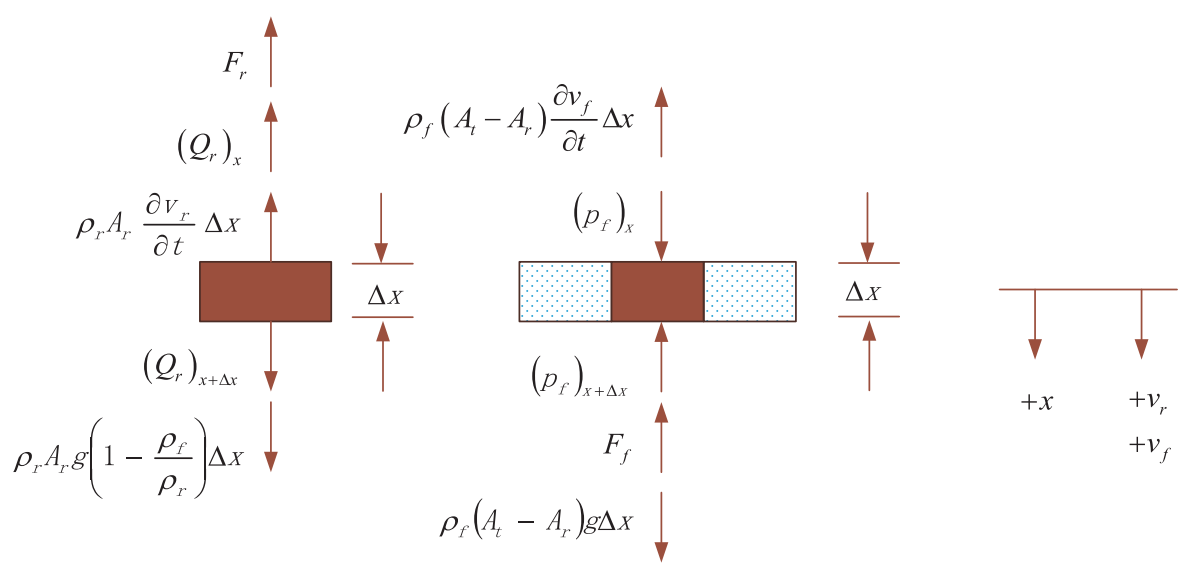

(a)

(b)

Figure 1: Dynamic model of rod and liquid column.

where

$v_{t}(x, t)$ is tube velocity, $\mathrm{m} / \mathrm{s}$;

$\mathrm{Q}_{t}(x, t)$ is inner force of tube, $\mathrm{N}$;

$E_{t}$ is rigidity of tube, $\mathrm{N} / \mathrm{m}^{2}$;

$F_{t}$ is resistance met with tube, $\mathrm{N} / \mathrm{m}^{2}$;

$A_{t}$ is inner area of tube, $\mathrm{m}^{2}$;

$A_{h}$ is outer area of tube, $\mathrm{m}^{2}$;

$\rho_{t}$ is density of tube, $\mathrm{kg} / \mathrm{m}^{3}$.

2.1.3. Dynamic Model of Liquid Column. By Assumption (2), the liquid column was treated as elastomer element. The force analysis of liquid element was shown in Figure 1(b); in accordance with force equilibrium condition, the kinematic equation of liquid column was as follows:

$$
\begin{aligned}
\rho_{f}\left(A_{t}-A_{r}\right) \frac{\partial v_{f}}{\partial t}= & -\left(A_{t}-A_{r}\right) \frac{\partial p_{f}}{\partial x}-F_{f} \\
& +\rho_{f}\left(A_{t}-A_{r}\right) g
\end{aligned}
$$

and

$$
E_{f} \frac{\partial v_{f}}{\partial x}=-\frac{\partial P_{f}}{\partial t}
$$

where

$v_{f}(x, t)$ is liquid column velocity, $\mathrm{m} / \mathrm{s}$;

$P_{f}$ is pressure of liquid, $\mathrm{N} / \mathrm{m}^{2}$;

$F_{f}$ is assistance met with liquid column, N.

Combinating (1) to (7), a set of mathematics models depicted the movement of rod-tube-liquid was achieved as follows:

$$
\begin{aligned}
& \rho_{r} A_{r} \frac{\partial v_{r}}{\partial t}=\frac{\partial f_{r}}{\partial x}+\rho_{r} A_{r} g\left(1-\frac{\rho_{f}}{\rho_{r}}\right)-F_{r} \\
& E_{r} A_{r} \frac{\partial v_{r}}{\partial x}=\frac{\partial f_{r}}{\partial t}
\end{aligned}
$$

$$
\begin{aligned}
\rho_{r}\left(A_{h}-A_{t}\right) \frac{\partial v_{t}}{\partial t}= & \frac{\partial f_{t}}{\partial x} \rho_{t} g\left(A_{h-} A_{t}\right)-F_{t} \\
E_{t}\left(A_{h}-A_{t}\right) \frac{\partial v_{t}}{\partial x}= & \frac{\partial f_{t}}{\partial t} \\
\rho_{f}\left(A_{t}-A_{r}\right) \frac{\partial v_{f}}{\partial t}= & -\left(A_{t}-A_{r}\right) \frac{\partial p_{f}}{\partial x}-F_{f} \\
& +\rho_{f}\left(A_{t}-A_{r}\right) g \\
E_{f} \frac{\partial v_{f}}{\partial x}= & -\frac{\partial P_{f}}{\partial t}
\end{aligned}
$$

The differential equations (8) are a three-dimensional wave mathematics model described the rod-tube-liquid column that can be used to calculate the forces and displacement at arbitrary section of rod.

2.2. Calculation of Damping Force Effected on the Oil Rod. The damping forces of the rod included three parts, of which the viscosity force $F_{r f}$ acts on the per unit length of rod surface by the liquid; the viscosity force $F_{c f}$ acts on the rod coupling; and the friction force $F_{r}$ acts on the per unit length of rod by the tube. The friction force was important depending on the well slope, but difficult to calculate.

The viscosity force action on the per unit length of the rod by liquid was as follows:

$$
F_{r f}=\frac{1}{2} \rho_{f} v_{f}\left|v_{f}\right| \pi D_{r} C_{1}
$$

The damping force acting on the every rod couplings by liquid was as follows:

$$
F_{c}=\frac{1}{2} \rho_{f} v_{f}\left|v_{f}\right|\left(A_{c}-A_{r}\right) C_{2}
$$

Assuming that the length of a rod was $l$, then the damping force acting on the convert unit length of rod was as follows:

$$
F_{c f}=\frac{\rho_{f} v_{f}\left|v_{f}\right|\left(A_{c}-A_{r}\right) C_{2}}{2 l}
$$


So, the resistance force of the rod was

$$
\begin{aligned}
F_{r} & =F_{c f}+F_{r f} \\
& =\frac{\rho_{f} v_{f}\left|v_{f}\right|\left(A_{c}-A_{r}\right) C_{2}}{2 l}+\frac{1}{2} \rho_{f} v_{f}\left|v_{f}\right| \pi D_{r} C_{1}
\end{aligned}
$$

where $C_{1}$ and $C_{2}$ were the nondimensional damping factors of the rod and the coupling, respectively.

$$
\begin{aligned}
& C_{1}=\frac{24}{R_{e}}\left[1 \pm \frac{R_{e}{ }^{\prime}}{R_{e}}\left(0.2+0.39 \cdot \frac{D_{r}}{D_{t}}\right)\right] \\
& C_{2} \\
& =\frac{5.2 \times 10^{4}\left(\left(D_{c} / D_{t}\right)-0.381\right)\left(2.77 \pm 1.69\left(R_{e}{ }^{\prime} / R_{e}\right)\right)}{R_{e}}
\end{aligned}
$$

where

$$
\begin{aligned}
& D_{r} \text { is the diameter of rod; } \\
& D_{t} \text { is the inner diameter of tube. }
\end{aligned}
$$

Reynolds numbers $R_{e}$ and $R_{e}{ }^{\prime}$ were related to the liquid velocity and the rod velocity, which were calculated by the following equations, respectively.

$$
\begin{gathered}
R_{e}=\frac{v_{f}\left(D_{t}-D_{r}\right) \rho_{f}}{\mu} \\
R_{e}{ }^{\prime}=\frac{v_{r}\left(D_{t}-D_{r}\right) \rho_{f}}{\mu}
\end{gathered}
$$

where

$\mu$ is the dynamic viscosity of liquid, $\mathrm{Pa} \cdot \mathrm{s}$.

Equations (13)-(16) were put in (12), so $F_{r}$ was as follows:

$$
\begin{aligned}
F_{r} & =12 \eta\left[\frac{\pi D_{r}}{D_{t}-D_{r}}\right. \\
& +\frac{2.77 \times 5.2 \times 10^{4}}{24}\left(\frac{D_{c}}{D_{t}}-0.381\right)^{2.57} \frac{\pi}{4} \\
& \left.\cdot \frac{D_{c}^{2}-D_{r}^{2}}{\left(D_{t}-D_{r}\right) l}\right] v_{f} \pm 12 \eta \\
& \cdot\left[\frac{\pi D_{r}}{D_{t}-D_{r}}\left(0.2+0.39 \frac{D_{r}}{D_{t}}\right)\right. \\
& +\frac{2.77 \times 0.61 \times 5.2 \times 10^{4}}{24}\left(\frac{D_{c}}{D_{t}}-0.381\right)^{2.57} \frac{\pi}{4} \\
& \left.\cdot \frac{D_{c}^{2}-D_{r}^{2}}{\left(D_{t}-D_{r}\right) l}\right] v_{r}
\end{aligned}
$$

When $v_{f}$ and $v_{r}$ had the same sign, they are positive or otherwise negative sign, so the above equation was as follows at last:

$$
F_{r}=b_{r} \cdot v_{r}-b_{f r} \cdot v_{f}
$$

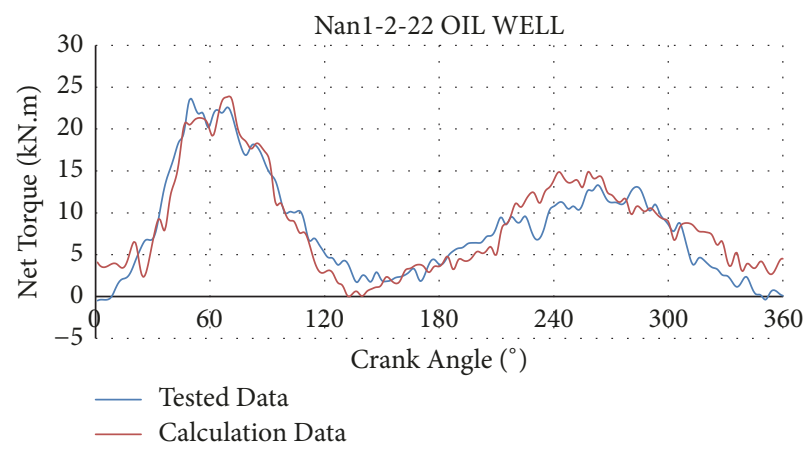

FIgURE 2: Torque comparison of Nan1-2-22 between measured data and calculated data.

$$
\begin{aligned}
b_{r}= & 12 \pi \eta\left[\left(0.2+0.39 \cdot \frac{D_{r}}{D_{t}}\right)+\frac{2.197}{24}\right. \\
& \left.\cdot\left(\frac{D_{c}}{D_{r}}-0.381\right)^{2.57} \cdot \frac{\left(D_{c} / D_{r}\right)^{2}-1}{1 / D_{r}}\right] \cdot \frac{1}{D_{t} / D_{r}-1} \\
b_{f r}= & 12 \pi \eta\left[1+\frac{1.601 \times 10^{4}}{24}\left(\frac{D_{c}}{D_{t}}-0.381\right)^{2.57}\right. \\
& \left.\cdot \frac{\left(D_{c} / D_{r}\right)^{2}-1}{1 / D_{r}}\right] \cdot \frac{1}{D_{t} / D_{r}-1}
\end{aligned}
$$

In a similar way, the resistance force acting on the tube was as follows:

$$
\begin{aligned}
F_{t} & =b_{t} v_{t}-b_{f t} v_{f} \\
b_{t} & =12 \pi \eta\left(0.2+0.39 \frac{D_{r}}{D_{t}}\right) \frac{1}{D_{t} / D_{r}-1} \\
b_{f t} & =12 \pi \eta \cdot \frac{1}{D_{t} / D_{r}-1}
\end{aligned}
$$

And the resistance force acting on the liquid column was as follows:

$$
F_{f}=-\left[F_{r}+F_{t}\right]
$$

2.3. Gearbox Net Torque. The gearbox output axial-torque was made of polished rod load torque, balance torque, walking bean inertial torque, and crank inertial torque. When the working velocity is constant, the calculate formula generally ignored the influent of walking beam inertia and crank inertia [15].

$$
T_{\mathrm{nh}}=\eta_{\mathrm{b}}^{\mathrm{m}}\left[W-B+\frac{J_{\mathrm{b}}}{A} \varepsilon_{\mathrm{b}}\right] \overline{T F}-M \sin (\theta+\tau)+J_{\mathrm{p} 3} \varepsilon
$$

\section{Dynamic Performance Analysis of Beam Pumping Unit}

3.1. Comparison between Measured Data and Calculated Data. Figure 2 was the net torque curves of Nan1-2-22 oil-well 


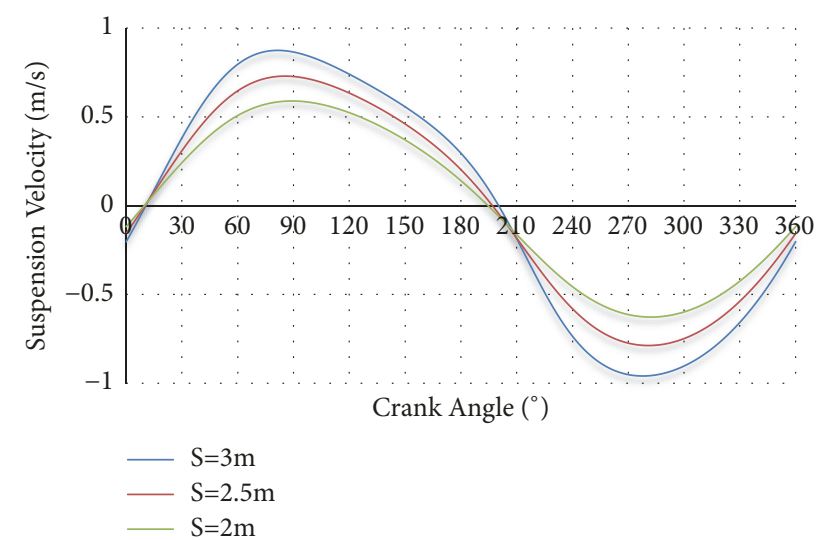

FIGURE 3: Impact of stroke on the suspension velocity.

in Daqing oilfield, which were measured and calculated, respectively. Its rod pumping was CYJ10-3-37HB running with 3 stroke, 6 frequency of stroke, and $990 \mathrm{~m}$ pump depth. The calculated torque curve was calculated by the $3 \mathrm{D}$ rodtube-liquid column wave equation built in this paper. Seen from Figure 2, the two curves of torque had the similar variation tendency that proved the $3 \mathrm{D}$ wave equation could be used to design the beam pumping units of oilfield.

\subsection{Basic Structure Parameters and Swabbing Parameters.} CYJY10-3-37HB was selected as objects to analyze its performance; the structure parameters and swabbing parameters were shown in Table 1 and Table 2, respectively.

3.3. Analysis of Performance of CYJY10-3-37HB. The stroke length of beam pumping units was decided by the length of crank. For a specific type of pumping unit, the crank length was correlated with strokes one-to-one. It was a linear proportional relationship between the suspension velocity and length of crank, with the increase of stroke; the absolute peak value of suspension velocity (peak value and valley value) increased. From Figure 3 we could see that, on the upstroke, the peak velocity shifted to 70 degrees of the crank angle. It is shown that the larger stroke was not of benefit for the actual balance effect to the beam pumping unit.

For CYJY10-3-37HB, the crank length determined the stroke size. From Figure 4, we could see that the direct proportion relationship between the stroke and the suspension acceleration was linear; the peak values of the acceleration curve of the three strokes obviously reflected the linear proportional relationship between them. The suspension acceleration was relatively larger near the top dead center; at this point the additional load also was large; therefore, it was noted that the start pumping point should avoid the top dead center.

The pumping velocity reflects the rotation speed of electrical motor; the rotation speed was also the crank speed. The suspension peak velocity was direct proportion to frequency of stroke. The peak values of the three curves can be seen from Figure 5; the change of frequency of stroke did not change the phase angle of the peak suspension velocity on the upstroke,
TABLE 1: Structure parameters and swabbing parameters.

\begin{tabular}{lc}
\hline Structure Parameters & Value \\
\hline Fore-arm Length $(\mathrm{mm})$ & 3000 \\
Aft-arm Length $(\mathrm{mm})$ & 1920 \\
Linkage Rod Length $(\mathrm{mm})$ & 3350 \\
Horizontal Throw $(\mathrm{mm})$ & 2500 \\
Crank Radius $(\mathrm{mm})$ & $880 / 740 / 600$ \\
Centre-Height $(\mathrm{mm})$ & 5290 \\
\hline
\end{tabular}

TABLE 2: Oil well condition and swabbing parameters.

\begin{tabular}{lc}
\hline Swabbing Parameters & Value \\
\hline Frequency of stroke $\left(\mathrm{min}^{-1}\right)$ & $3,6,9$ \\
Stroke $(\mathrm{m})$ & $2,2.5,3$ \\
Depth of Plunger $(\mathrm{m})$ & 980 \\
Working Fluid Level (m) & 550 \\
Pump Diameter (mm) & 56 \\
Rod Diameter (mm) & $19 / 22$ \\
Tube Diameter (mm) & 76 \\
Water Cut $(\%)$ & 92 \\
\hline
\end{tabular}

and the position of the crank angle was generally located at 85 degree. Therefore, the phase angle of the balance weight was not affected by the frequency of stroke, but it affects the weight of the counterweight.

Figure 6 showed that the frequency of stroke is quadratic proportional to suspension acceleration. With the frequency of stroke increasing, suspension acceleration would rapidly increase. Therefore, the increasing of frequency of stroke would cause a sharp increase of dynamic polished rod load. Especially at the top dead point, suspension acceleration increased very significantly.

As shown in Figure 7, the impact of stroke on the maximum and minimum polished rod load was not large; comparing to $2 \mathrm{~m}$, the maximum polished rod load of $2.5 \mathrm{~m}$ and $3 \mathrm{~m}$ stroke increased by $1.37 \%$ and $4.66 \%$, respectively, and the minimum polished rod load reduced by $4.64 \%$ and $8.80 \%$, respectively. With the stroke increasing, the entire work area increased.

As shown in Figure 8, the impact of frequency of stroke on the maximum and minimum polished rod load was very obvious. Comparing to the 3 frequency of stroke, the maximum polished rod load of 6 and 9 frequency of stroke increased by $10.26 \%$ and $22.31 \%$, respectively, the minimum load decreased by $9.61 \%$ and $19.62 \%$, respectively. Increasing of frequency of stroke would increase the suspension acceleration, so that the inertial load would increase. This also contributed to the rapid increasing of polished rod load with the increase of the frequency of stroke.

Figure 9 was a diagram of the torque curves comparison with different frequency of stroke in the case where the torque balance (torque balance is the ratio between the downstroke and upstroke peak torques) was one. With the frequency of stroke increasing, the peak torque increased. Comparing to 3 frequency of stroke, the maximum torque of 6 and 9 frequency of stroke increased by $16.98 \%$ and $65.03 \%$, 


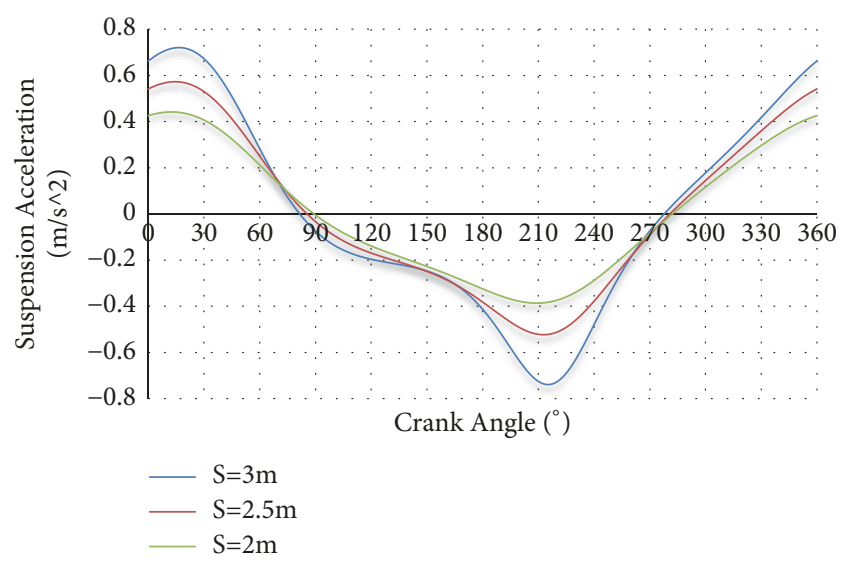

FIGURE 4: Impact of stroke on the suspension acceleration.

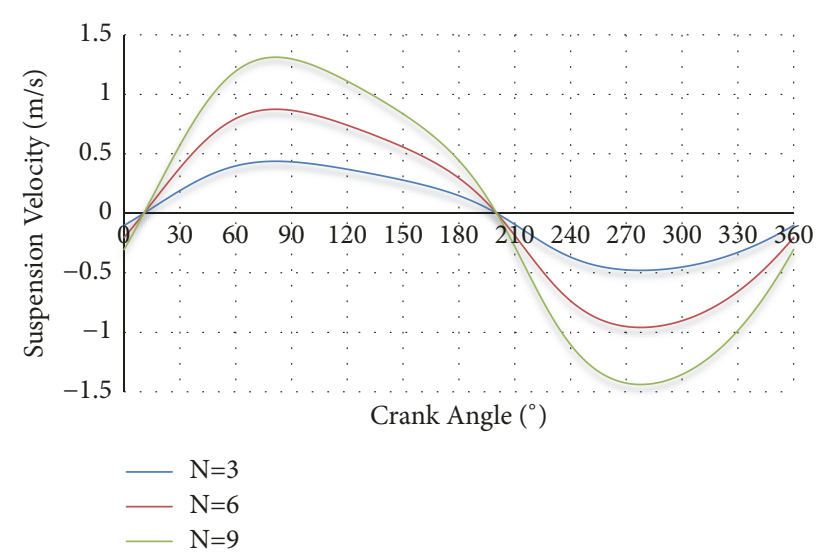

FIGURE 5: Impact of the frequency of stroke on the suspension velocity.

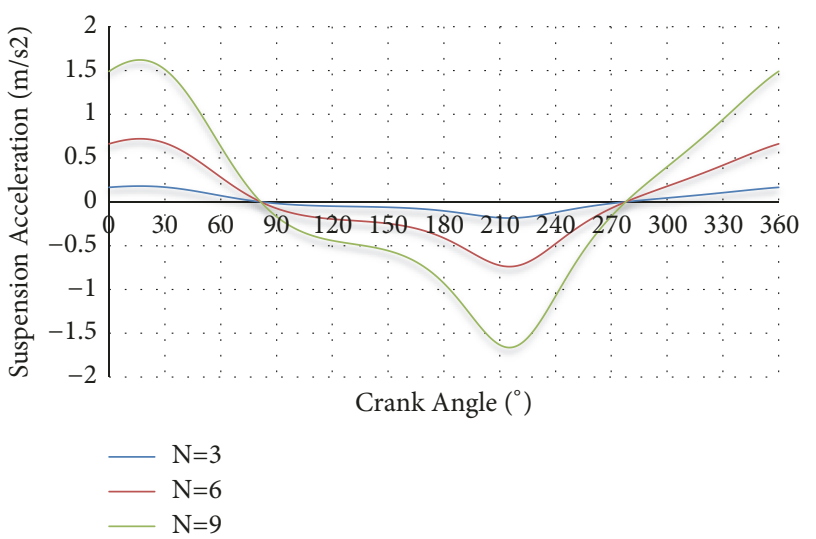

FIGURE 6: Impact of frequency of stroke on suspension acceleration.

respectively, but the valley values were all small. The structure features of CYJY10-3-37HB pumping unit could not avoid the negative torque mainly distributed in the scope of 102 degrees to 135 degrees and nearly the dead point. The increasement of frequency of stroke would have bigger influence on the torque curves.

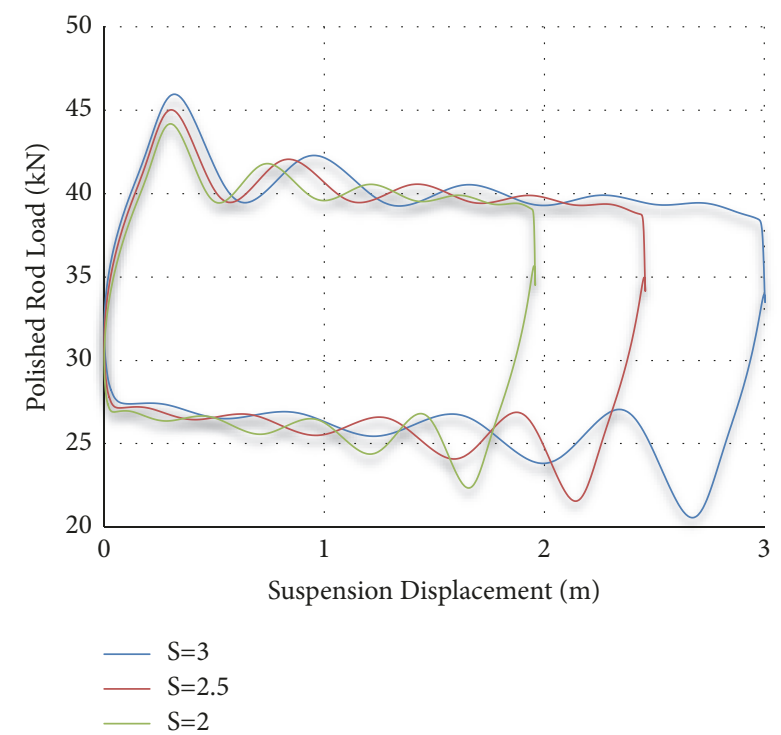

FIGURE 7: Impact of stroke on the polished rod load.

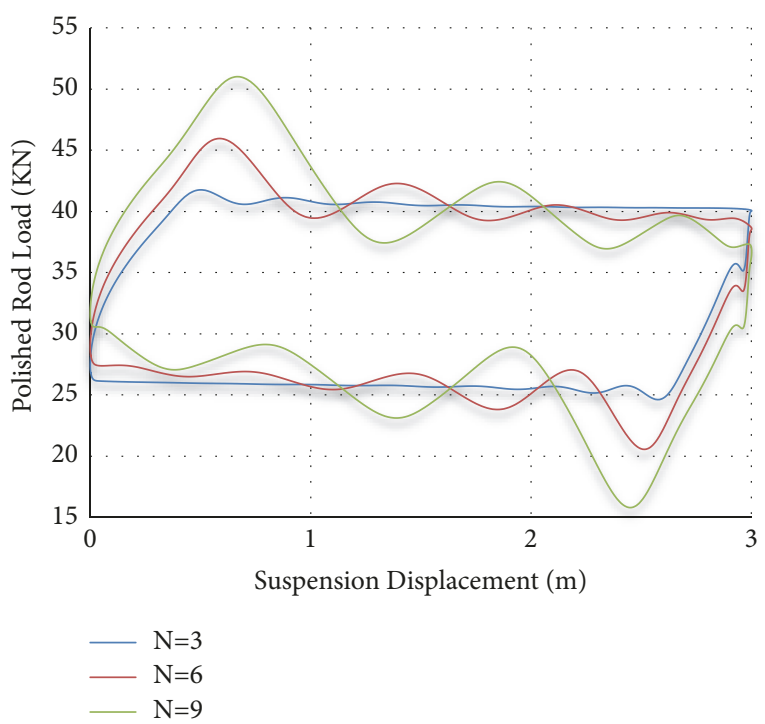

Figure 8: Impact of frequency of stroke on polished rod load.

Figure 10 shows the effect of stroke on torque curve of beam pumping unit when the torque degree of balance was one. Increasement of the stroke could cause a larger increase of peak torque, comparing to the $2 \mathrm{~m}$ and the maximum torque of $2.5 \mathrm{~m}$ and $3 \mathrm{~m}$ stroke increased by $30.68 \%$ and $69.27 \%$, respectively. The absolute valley value increased very little; only the $3 \mathrm{~m}$ stroke was more obvious than the other two. Seen from the increasement ratio, stroke would influence the torque more than the frequency of stroke, especially the negative value in the valley much more than the frequency of stroke.

\section{Conclusion}

To accurately and reliably calculate the dynamic load of the rod pumping, we considered the rod, the tube, and the 


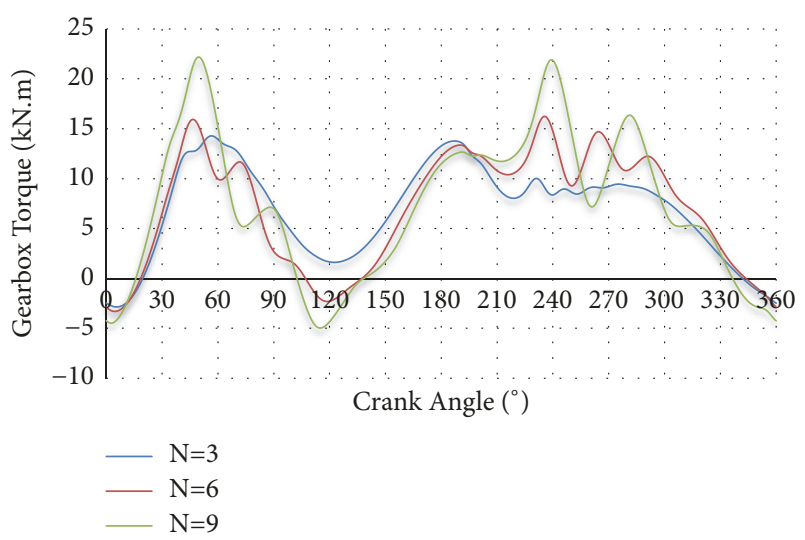

Figure 9: Impact on torque by frequency of stroke.

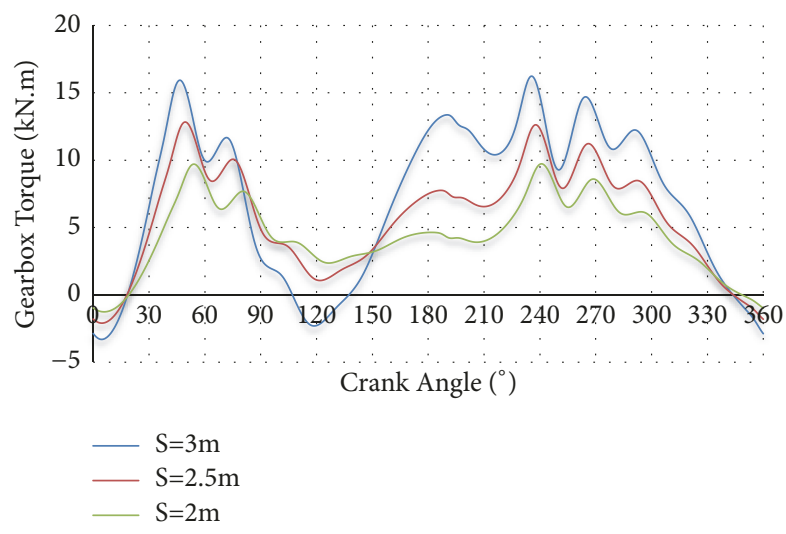

Figure 10: Stroke's impact on torque.

liquid column and established a 3D dynamic wave model of rod pumping, which were made up of a set of partial differential equations. By a comparison between the tested torque curve and the calculated torque curve, this advanced model was proved to be more reliable and more accurate than other semiempirical model. We analyzed the working performance of beam pumping units with type of CYJY10-337HB. Calculated results indicated that, with the increasing of stroke and frequency of stroke, suspension peak velocity, suspension peak acceleration, polished rod load, and peak torque of gearbox increased. Stroke effect on peak torque of gearbox, which is very important for system optimization design, was much bigger than the effect of the frequency of stroke. This 3D dynamic wave model considered the liquid column load in this paper had higher accuracy than the semiempirical, $1 \mathrm{D}$ and $2 \mathrm{D}$ equations. This paper provided a valuable theoretical model for the pumping well system. In the future, we may improve this 3D model to be suitable for deviated wells and horizontal wells, also to be suitable for high gas fractions wells.

\section{Conflicts of Interest}

The authors declare that they have no conflicts of interest.

\section{Acknowledgments}

The authors acknowledge the Natural Science Foundation of China (no. 51774091), Heilongjiang Province Postgraduate Pedagogy Innovation Engineering Funded Projects (Fund no. JGXM_HLJ_2016043), and Project Funded By China Postdoctoral Science Foundation (No. 2018T110268).

\section{References}

[1] E. Kemler, "An Investigation of Experimental Methods of Determining Sucker-rod Loads," Transactions of the AIME, vol. 118, no. 01, pp. 89-99, 2013.

[2] M. Halderson, "Artificial brain is required to solve the suckerrod pumping problem," API Drilling and Production Practice, vol. 1, no. 1, pp. 210-218, 1953.

[3] J. Norton, "Dynamic loads in sucker rods," The Petroleum Engineer, vol. 4, no. 1, p. 1726, 1960.

[4] W. Synder, "How to find downhole forces and displacements," Oil \& Gas Journal, vol. 8, no. 8, pp. 96-99, 1963.

[5] S. Gibbs, "Predicting the Behavior of Sucker-Rod Pumping Systems," Journal of Petroleum Technology, vol. 15, no. 07, pp. 769-778, 2013.

[6] J. Chacin and J. Purcupile, "A New Model for Studying Oilwell Pumping Installations," in Proceedings of the SPE Annual Technical Conference and Exhibition, Dallas, Texas.

[7] D. R. Doty and Z. Schmidt, "Improved model for sucker rod pumping," Society of Petroleum Engineers Journal, vol. 23, no. 1, pp. 33-41, 1983.

[8] S. Lelia and R. Evans, "A coupled rod and fluid dynamic model for predicting the behavior of sucker-rod pumping systems," SPE Production \& Facilities, vol. 10, no. 1, pp. 26-33, 1995.

[9] G. Yu, Y. Wu, and G. Wang, "Three-dimensional vibration in a sucker rod beam pumping system," ACTA Petroleum SINICA, vol. 10, no. Issue, pp. 16-21, 1989.

[10] Y. Wu, Z. Liu, and G. Zhao, "Sucker rod beam pumping unit and technology-pump jack," Petroleum Industry Publishing Company, vol. 35, no. 2, pp. 128-124, 1994.

[11] I. N. Shardakov and I. N. Wasserman, "Numerical modelling of longitudinal vibrations of a sucker rod string," Journal of Sound and Vibration, vol. 329, no. 3, pp. 317-327, 2010.

[12] M. Z. Jiang and Y. M. Cai, "Study on changes of operation parameters of variable-speed driven pumping wells," Oil Field Equipment, vol. 39, no. 10, pp. 4-7, 2013.

[13] E. Ferrigno and J. Zabala, "Pumping unit gearbox torque determination method based on motor behavior," in Proceedings of the 2015 SPE Artificial Lift Conference - Latin America and Caribbean, pp. 593-598, Brazil, May 2015.

[14] L.-M. Lao and H. Zhou, "Application and effect of buoyancy on sucker rod string dynamics," Journal of Petroleum Science and Engineering, vol. 146, pp. 264-271, 2016.

[15] M. Xing, "Response analysis of longitudinal vibration of sucker rod string considering rod buckling," Advances in Engineering Software, vol. 99, pp. 49-58, 2016. 


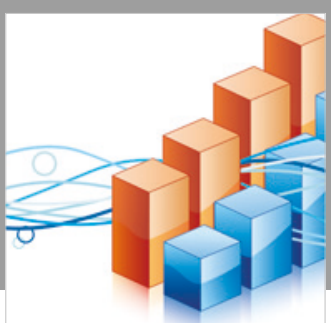

Advances in

Operations Research

\section{-n-m}
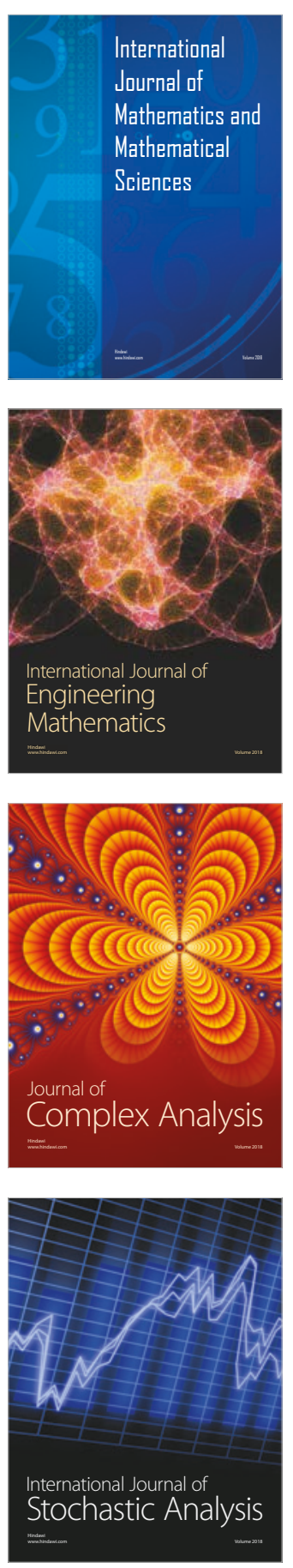
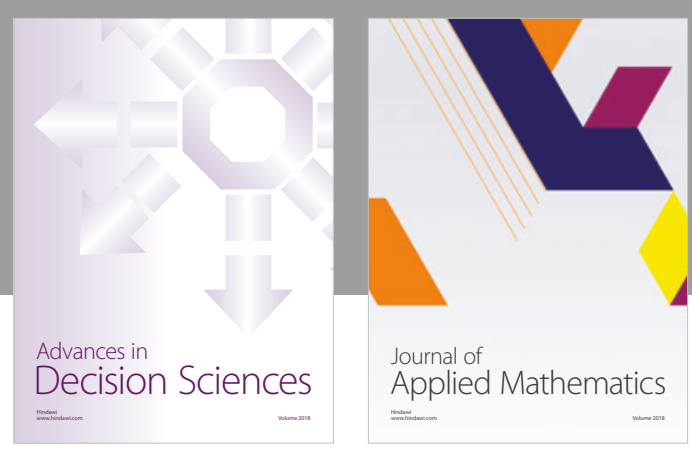

Journal of

Applied Mathematics
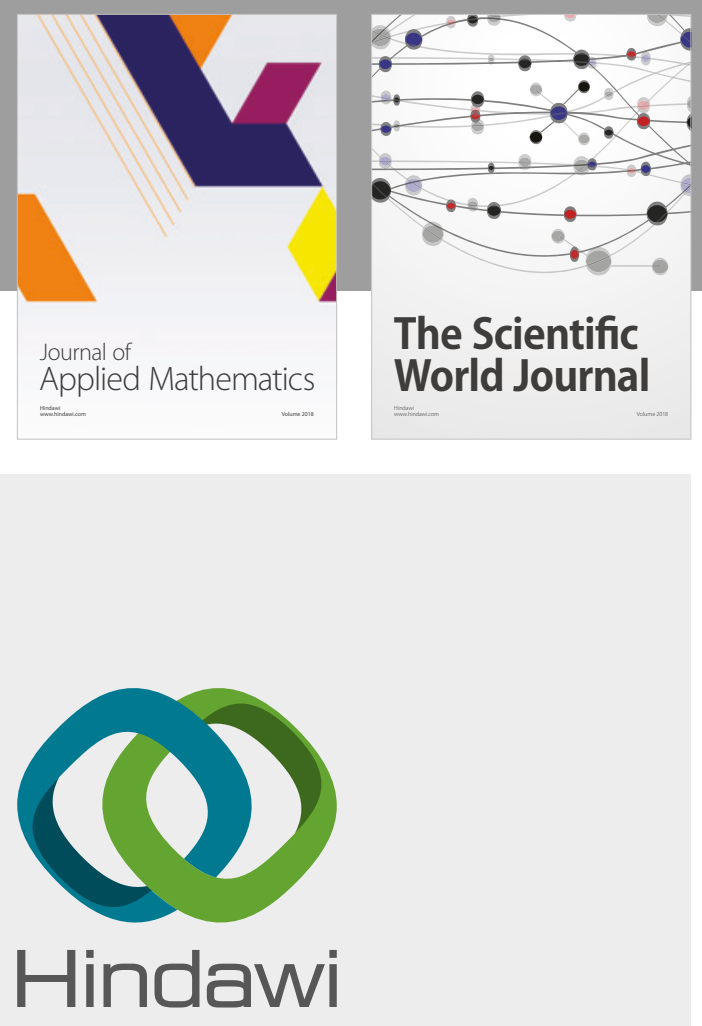

Submit your manuscripts at

www.hindawi.com

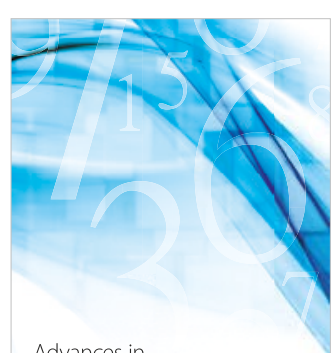

Advances in
Numerical Analysis
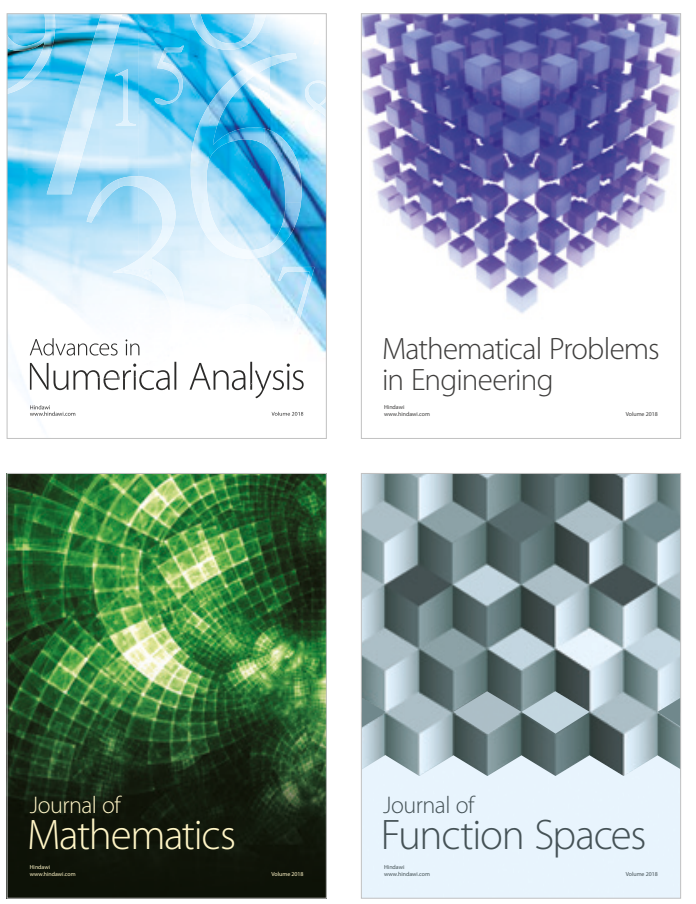

Mathematical Problems in Engineering

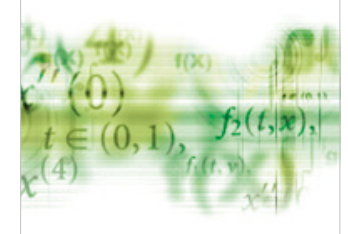

International Journal of

Differential Equations

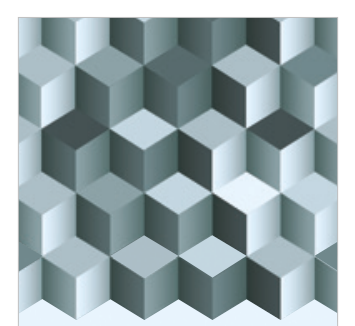

Journal of

Function Spaces

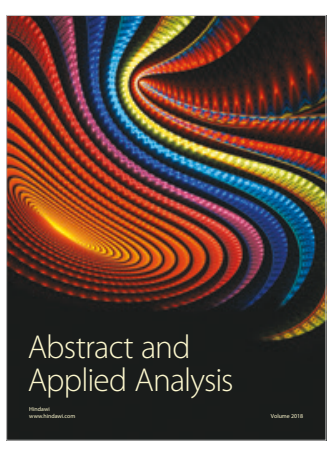

The Scientific

World Journal

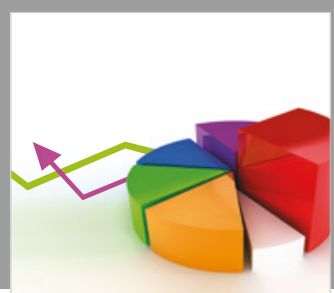

Journal of

Probability and Statistics
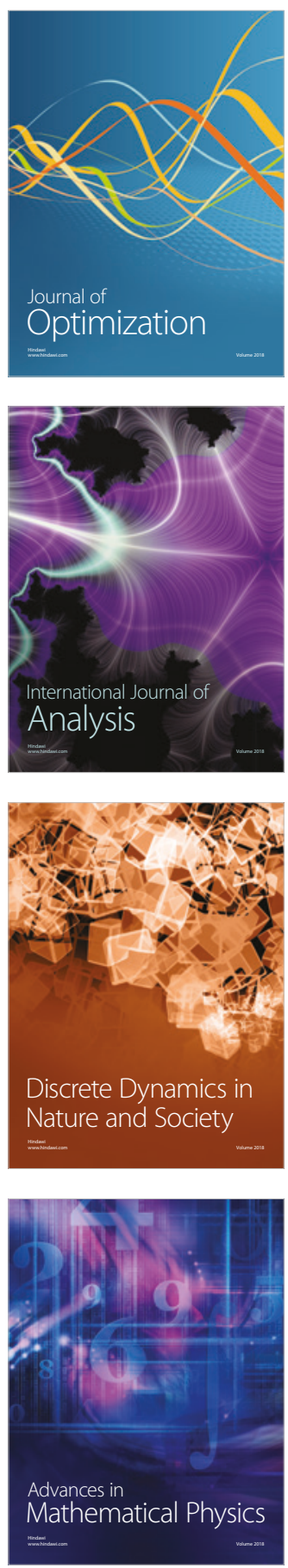